\title{
Cell layers and neuropil: contrast-enhanced MRI of mouse brain in vivo
}

\author{
Takashi Watanabe $^{\mathrm{a} *}$, Jens Frahm ${ }^{\mathrm{a}}$ and Thomas Michaelis ${ }^{\mathrm{a}}$
}

\begin{abstract}
Contrast-enhanced $T_{1}$-and $T_{2}$-weighted $\mathrm{MRI}$ at $9.4 \mathrm{~T}$ and in-plane resolutions of 25 and $30 \mu \mathrm{m}$ has been demonstrated to differentiate between neural tissues in mouse brain in vivo, including granule cell layers, principal cell layers, general neuropil, specialized neuropil and white matter. In $T_{1}$-weighted MRI of the olfactory bulb, hippocampus and cerebellum, contrast obtained by the intracranial administration of gadopentetate dimeglumine (Gd-DTPA) reflects the extra- and intracellular spaces of gray matter in agreement with histological data. General neuropil areas are highlighted, whereas other tissues present with lower signal intensities. The induced contrast is similar to that in plain $T_{2}$-weighted MRI, but offers a 16-30-fold higher contrast-to-noise ratio. Systemic administration of manganese chloride increases the signalto-noise ratio in $T_{1}$-weighted MRI to a significantly greater extent in principal cell layers and specialized neuropil than in granule cell layers, whereas gadolinium-enhanced MRI indicates no larger intracellular spaces in these tissues. Granule cell layers are enhanced no more than general neuropil by manganese, whereas gadolinium-enhanced MRI indicates significantly larger intracellular spaces in the cell layers. These discrepancies suggest that the signal increase after manganese administration reflects cellular activity which is disproportionate to the intracellular space. As a result, principal cell layers and specialized neuropil become highlighted, whereas granule cell layers, general neuropil and white matter present with lower signal intensities. Copyright $\odot 2013$ John Wiley \& Sons, Ltd.
\end{abstract}

Keywords: brain mapping; contrast media; gadolinium-DTPA; histology; intraventricular injections; manganese chloride; staining; subcutaneous injections

\section{INTRODUCTION}

MRI and MRS are expected to play a central role in translational biomedical research (1-3), for example: (i) in morphological, functional and biochemical phenotyping of the brain in vivo; and (ii) in the evaluation of novel therapeutic interventions in animal models of human diseases. Nonetheless, abnormal MR findings may still need to be verified by other techniques because of their microscopic size and/or subtle alteration of MR properties. Therefore, additional means of contrast enhancement by exogenous compounds are highly desirable, which bridge the gap between in vivo MR data and post-mortem analyses, e.g. histological staining.

In the central nervous system of vertebrates, cell bodies of neurons are often assembled as cellular layers which play specific roles as functional units. Packed tightly with cell bodies and oriented parallel to the surface of the brain, a cellular layer is often flanked by tissue with axonal and dendritic fibers (i.e. neuropil) as primary components. In mammalian brain, the lamination - or differentiation into specific layers - is most characteristically seen in the olfactory bulb, hippocampus and cerebellum (4). Based on the smaller $T_{1}$ and $T_{2}$ relaxation times and the slower diffusion of water protons in intracellular spaces compared with free water (5), a cellular layer was identified by MRI first in the hippocampus ex vivo (6). In living mice, cellular layers have been identified in $T_{1}$-weighted (T1W) (7), $T_{2}$-weighted (T2W) (8) and $T_{2}{ }^{*}$-weighted (9) MRI. The contrast in T1W MRI can be improved by delivering manganese $\left(\mathrm{Mn}^{2+}\right)$ to the brain (10), because this $T_{1}$-shortening ion accumulates in cells and thus predominantly in cellular layers. Alternatively, extracellular agents may be used for contrast enhancement, because they are expected to predominantly diffuse into the neuropil rather than the cellular layers.

The purpose of this study was to explore the potential of contrast enhancement between cellular layers and neuropil in MRI. The effect of the intracranial administration of gadopentetate dimeglumine (Gd-DTPA), as well as the systemic administration of $\mathrm{Mn}^{2+}$, on T1W MRI of the olfactory bulb, hippocampus and cerebellum of anesthetized mice was examined. The results were also compared with T2W MRI before and after systemic administration of $\mathrm{Mn}^{2+}$, as well as with histological data from the literature $(11,12)$.

\section{MATERIALS AND METHODS}

\section{Animals and contrast agents}

Eight female mice (NMRl; age, 8-16 weeks; body weight, 30-48 g) were studied in accordance with German animal protection laws after approval by the responsible governmental authority. Four mice received an intraventricular injection of Gd-DTPA solution (5.0 $\mu \mathrm{L}, 100 \mathrm{~mm}$, Magnevist dissolved in physiological saline, Schering, Berlin, Germany) as well as injections ( $0.3 \mu \mathrm{L}$ into each

\footnotetext{
* Correspondence to: T. Watanabe, Biomedizinische NMR Forschungs $\mathrm{GmbH}$, 37070 Göttingen, Germany.

E-mail: twatana@gwdg.de

a T. Watanabe, J. Frahm, T. Michaelis

Biomedizinische NMR Forschungs GmbH am Max-Planck-Institut für Biophysikalische Chemie, Göttingen, Germany
}

Abbreviations used: CNR, contrast-to-noise ratio; Gd-DTPA, gadopentetate dimeglumine; SNR, signal-to-noise ratio; $T 1 W, T_{1}$-weighted; T2W, $T_{2}$-weighted. 
side) of $50 \mathrm{~mm}$ Gd-DTPA into the olfactory bulbs, as described previously $(13,14)$. The other four mice received manganese chloride $(0.5 \mathrm{mmol} / \mathrm{kg}$ body weight) subcutaneously. For in vivo $\mathrm{MRI}$, the animals were anesthetized, intubated and artificially ventilated as described previously (15). A reproducible and reliable immobilization of the mouse head and receiver coil in the isocenter of the magnet was ensured by the Göttingen animal bed (16).

\section{MRI}

MRI was performed at 9.4 T (Bruker Biospin MRI GmbH, Ettlingen, Germany) before and after contrast media administration, i.e. 20-210 min after intracranial Gd-DTPA injection or 2-3 days after systemic manganese administration. Radiofrequency excitation and signal reception were accomplished with the use of a birdcage resonator (inner diameter, $72 \mathrm{~mm}$ ) and a four-channel phased-array surface coil, respectively (both Bruker Biospin MRI GmbH).

T1W MRI was performed with a three-dimensional gradient-echo MRI sequence (spoiled fast low-angle shot; TR/TE = $22 \mathrm{~ms} / 7.6 \mathrm{~ms}$; flip angle, $25^{\circ}$ ) at a resolution of $30 \times 30 \times 300$ or $25 \times 25 \times 250 \mathrm{\mu m}^{3}$. Measuring times varied between 12 and $96 \mathrm{~min}$. T2W MRI data were acquired with a three-dimensional fast spin-echo MRI sequence ( $T R=4.2 \mathrm{~s}$; eight differently phaseencoded echoes; measuring time, $2 \mathrm{~h} 41 \mathrm{~min}$ ) at a resolution of $30 \times 30 \times 300 \mu \mathrm{m}^{3}$. TEs of 48 and $80 \mathrm{~ms}$ were found to best delineate the Purkinje and pyramidal cell layers, respectively, in pilot studies.

$T_{1}$ relaxation times were determined using a spin-echo saturation recovery method with $\mathrm{TE}=10 \mathrm{~ms}$, in-plane resolution of $117 \times 117 \mu \mathrm{m}^{2}$, slice thickness of $234 \mu \mathrm{m}$ and nine slices. Seven TR values ranging from 200 to $10000 \mathrm{~ms}$ led to a total measuring time of $32 \mathrm{~min}$.

\section{Data evaluation}

For the evaluation of signal intensities, anatomically defined crosssections were obtained from the original three-dimensional MRI datasets by multiplanar reconstructions using software supplied by the manufacturer (Paravision 5.0, Bruker Biospin MRI GmbH). The plane crossing the anterior and posterior commissure served as a reference for the selection of standardized sections to facilitate comparisons with minimized intra- and inter-individual variability. For the normalization of signal intensities, the caudate putamen was used as an internal reference for each animal. The signal-tonoise ratio (SNR), defined as the mean signal intensity divided by the standard deviation of the noise, was obtained from images with a resolution of $30 \times 30 \times 300 \mu \mathrm{m}^{3}$. The contrast-to-noise ratio (CNR) was obtained by taking the difference between the SNR values. The analysis followed a strategy previously developed for intra- and inter-individual comparisons of MR images after manganese administration $(7,15)$. Significant differences between regions of interest were determined by Student's paired two-sided $t$-test (two-sample comparison of means, unequal variances assumed).

For $T_{1}$ values, a region of interest (six voxels) was selected in a standardized manner relative to obvious structural landmarks using a manual segmentation of a mid-sagittal image for the cerebellar cortex, as well as lateral sections for the olfactory bulb $(1.0 \mathrm{~mm})$, somatosensory cortex $(1.5 \mathrm{~mm})$ and hippocampal formation $(2.0 \mathrm{~mm})$. The corresponding mean MRI signal intensities as a function of TR were fitted with a single exponential.

On the assumption that (i) Gd-DTPA equilibrates between extracellular fluids of different regions (17), (ii) water protons of pertinent tissue compartments are in fast exchange $(18,19)$ and (iii) the extracellular space of the somatosensory cortex of young adult wild-type mice is $18 \%$ (20), the extracellular space in the left hippocampal formation and cerebellar cortex was estimated from the ratio of $\Delta R_{1}$ (i.e. the increase in $1 / T_{1}$ caused by $\mathrm{Gd}$ DTPA) of each region to $\Delta R_{1}$ in the somatosensory cortex, following the method described previously (14), but with the assumption of $18 \%$ for the extracellular space of the cortex.

\section{RESULTS}

As shown in Fig. $1 \mathrm{~A}-\mathrm{C}$, both intracranial administration of $\mathrm{Gd}$ DTPA and systemic administration of $\mathrm{Mn}^{2+}$ cause a general signal increase in T1W MRI of the mouse brain. However, although the induced contrast between white and gray matter is similar, the contrast within gray matter, e.g. in the hippocampal formation, is almost opposite. Compared with gadolinium-enhanced T1W MRI (Fig. 1B), plain T2W MRI (Fig. 1D) provides a similar, but weaker, contrast despite a much longer measuring time. The contrast induced in T1W MRI of the hippocampal formation by Gd-DTPA administration (Fig. 1E) is very similar to that in a Nissl stain of nerve cell bodies (Fig. 1F). This close resemblance indicates that the contrasts induced in gray matter by both techniques reflect the relative distribution of extra- and intracellular spaces. Moreover, gadolinium-enhanced MRI presents white matter with lower signal intensity increases than gray matter, and thus distinguishes between the two tissues more clearly than does histological staining. The gross resemblance of the brain in manganeseenhanced MRI (Fig. 1G) to that in histology (Fig. 1H) is in line with the assumption that $\mathrm{Mn}^{2+}$ ions accumulate in the intracellular fluid of nerve cell bodies, despite some differences seen in the hippocampal formation.

\section{Olfactory bulb}

As shown in Fig. 2A, B, there is a close resemblance of the contrast in gadolinium-enhanced MRI to that in Nissl stains of cell bodies. Gd-DTPA highlights the inner and outer plexiform layers in agreement with their sparse staining, whereas cellular layers present with low signal intensity in agreement with their dense staining. In particular, gadolinium-enhanced MRI yields low signal intensity for the granule cell layer in agreement with its dense staining. However, white matter presents with low signal intensity, but it is not stained histologically. In the granule cell, mitral cell, external plexiform and glomerular layer, Gd-DTPA increases the SNR at 96 min after injection by 130\%, 115\%, 221\% and $153 \%$, respectively $(n=4)$. These values correspond to normalized signal intensities of $0.74 \pm 0.11,0.75 \pm 0.11,1.08 \pm 0.11$ and $0.73 \pm 0.16$ at a resolution of $25 \times 25 \times 250 \mu \mathrm{m}^{3}$ (white matter $0.50 \pm 0.06)$.

Figure $2 \mathrm{C}, \mathrm{D}$ demonstrates that $\mathrm{Mn}^{2+}$ ions highlight the mitral cell as well as the glomerular layer in T1W MRI, whereas neuropil and white matter present with low intensity in agreement with Nissl staining. In contrast with histology, however, manganeseenhanced MRI does not highlight the granule cell layer despite its dense staining (black arrowheads). In the granule cell, mitral cell, external plexiform and glomerular layers, $\mathrm{Mn}^{2+}$ ions increase the SNR 2 days after injection by 10\%, 46\%, 16\% and 45\%, 


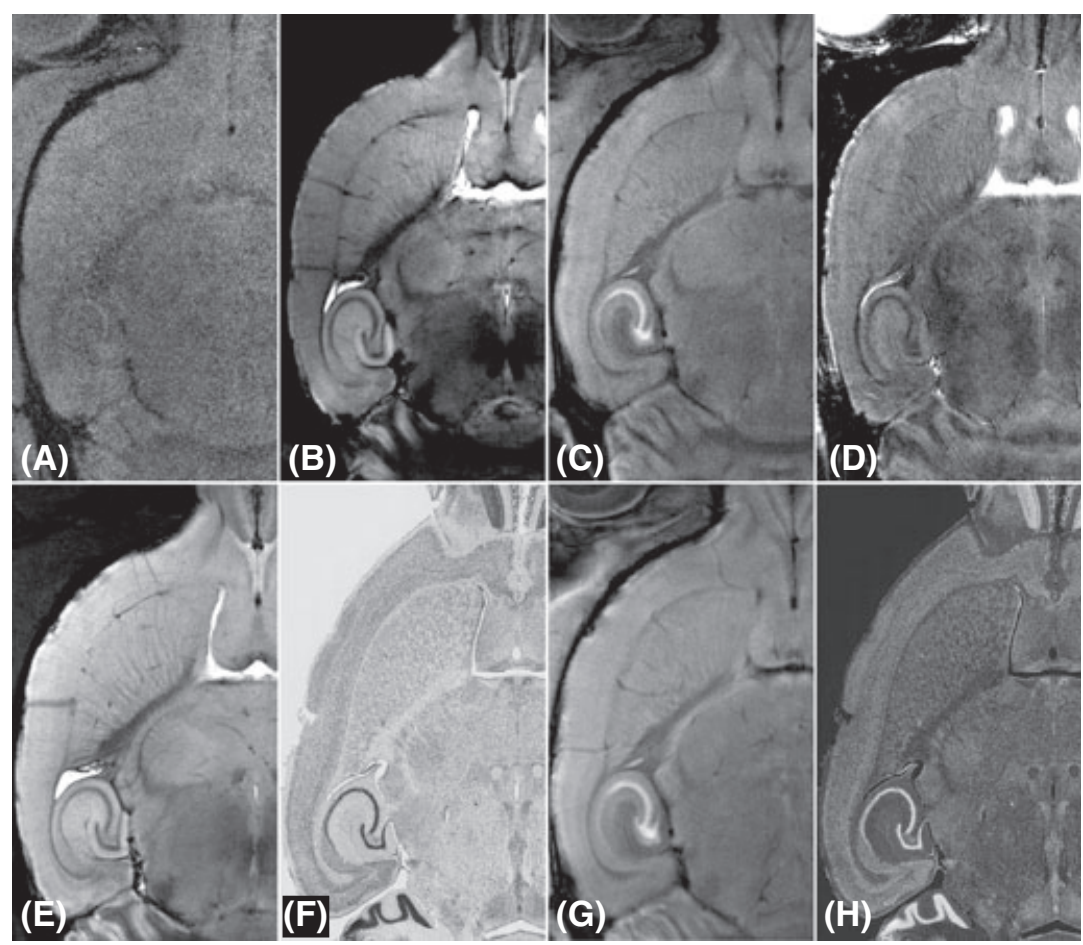

Figure 1. Right forebrain in horizontal sections. (A) Plain $T_{1}$-weighted (T1W) MRI (12 min, $\left.30 \times 30 \times 300 \mu \mathrm{m}^{3}\right)$. T1W MRI 90-102 min after gadopentetate dimeglumine (Gd-DTPA) injection (B) and 2 days after $\mathrm{MnCl}_{2}$ injection (C). (D) $T_{2}$-weighted (T2W) MRI (161 min, $\left.30 \times 30 \times 300 \mu \mathrm{m}^{3}\right)$. (E) T1W MRI (48 min, $25 \times 25 \times 250 \mu^{3}$ ) 150-198 min after Gd-DTPA administration. (F) Nissl stain of cell bodies (slide number 39 in (11)). (G) T1W MRI $\left(96 \mathrm{~min}, 25 \times 25 \times 250 \mu \mathrm{m}^{3}\right.$ ) 3 days after $\mathrm{MnCl}_{2}$ administration. $(\mathrm{H})$ Nissl stain (contrast inverted). For details, see text.

respectively $(n=4)$. In particular, the $\mathrm{Mn}^{2+}$ enhancement is significantly $(p<0.05)$ higher in the mitral than the granule cell layer despite a non-significant $(p=0.47)$ difference in Gd-DTPA enhancement between these tissues. The $\mathrm{Mn}^{2+}$ enhancement is also significantly $(p<0.05)$ higher for the glomerular than the granule cell layer despite a non-significant $(p=0.18)$ difference in Gd-DTPA enhancement. Further, the enhancement by $\mathrm{Mn}^{2+}$ is not significantly $(p=0.43)$ different between the granule cell and the external plexiform layer, although the enhancement by Gd-DTPA is significantly $(p<0.05)$ higher for the external plexiform layer. As a result, the corresponding normalized signal intensities in the granule cell layer, mitral cell layer, external plexiform layer, glomerular layer and white matter are $0.69 \pm 0.21$, $1.16 \pm 0.37,0.73 \pm 0.20,1.03 \pm 0.23$ and $0.53 \pm 0.11 \quad(n=3)$ at a resolution of $25 \times 25 \times 250 \mu \mathrm{m}^{3}$.

Plain T2W MRI (Fig. 2E) provides a similar contrast to gadolinium-enhanced T1W MRI (Fig. 2F), although T2W MRI only partly distinguishes the mitral cell layers from the granule cell layers at a much longer measuring time. $\mathrm{Mn}^{2+}$ ions improve the delineation of the mitral cell layers in T2W MRI (Fig. 2G), in agreement with the finding in manganese-enhanced T1W MRI (Fig. $2 \mathrm{H}$ ). $\mathrm{Mn}^{2+}$ ions decrease the SNR in T2W MRI 2 days after injection by $32 \%$ in the mitral cell layer, but by only $6 \%$ in the external plexiform layer, so that the respective CNR increases by $53 \%(n=4)$.

\section{Hippocampal formation}

As shown in Fig. 3A, B, there is again similar cellular contrast in MRI of Gd-DTPA-treated tissue and Nissl-stained histology. Gd-DTPA highlights neuropil areas in agreement with their sparse staining, whereas the densely packed cell layers present with low signal intensity. The induced contrast persists for several hours. Gadolinium-enhanced MRI exhibits the lowest signal intensity for the most densely packed granule cell layer (black arrowhead) and pyramidal cell layer in agreement with their dense staining. The tissue areas with moderate staining, i.e. the stratum multiforme, subiculum and presubiculum, present with correspondingly low signal intensities. In addition, gadoliniumenhanced MRI depicts white matter (black arrows in Fig. 3B) and the stratum lucidum, although they are not stained histologically. In the granule cell layer, pyramidal cell layer, stratum lacunosummoleculare, stratum multiforme and white matter, Gd-DTPA increases the SNR at 96 min after injection by $86 \%, 77 \%, 227 \%$, $160 \%$ and $117 \%$, respectively $(n=4)$, with normalized intensities of $0.65 \pm 0.07,0.62 \pm 0.05,1.05 \pm 0.09,0.94 \pm 0.05$ and $0.62 \pm 0.07$ at a resolution of $25 \times 25 \times 250 \mu \mathrm{m}^{3}$ (stratum lucidum $0.83 \pm 0.08$ ).

As stated earlier, manganese-enhanced T1W MRI (Fig. 1G) exhibits different contrast relative to Nissl stains (Fig. 1H) for cell bodies. Here, manganese-enhanced MRI (Fig. 3C) is compared with another histological technique (Fig. 3D), which highlights the strata lucidum (white arrow) and multiforme (asterisk) because of their high concentration of glutamic acid decarboxylase. The comparison reveals that $\mathrm{Mn}^{2+}$ ions most intensely enhance the specialized neuropil. This is in disagreement with the assumption that manganese enhancement correlates with the volume of the intracellular spaces, which are largest in the pyramidal or granule cell layers. In the granule cell layer, pyramidal cell layer, stratum lacunosum-moleculare, stratum multiforme and white matter, $\mathrm{Mn}^{2+}$ ions increase the SNR 2 days after injection by $35 \%, 61 \%$, $21 \%, 84 \%$ and $33 \%$, respectively $(n=4)$. The $\mathrm{Mn}^{2+}$ enhancement is significantly $(p<0.005)$ higher for the pyramidal than the 

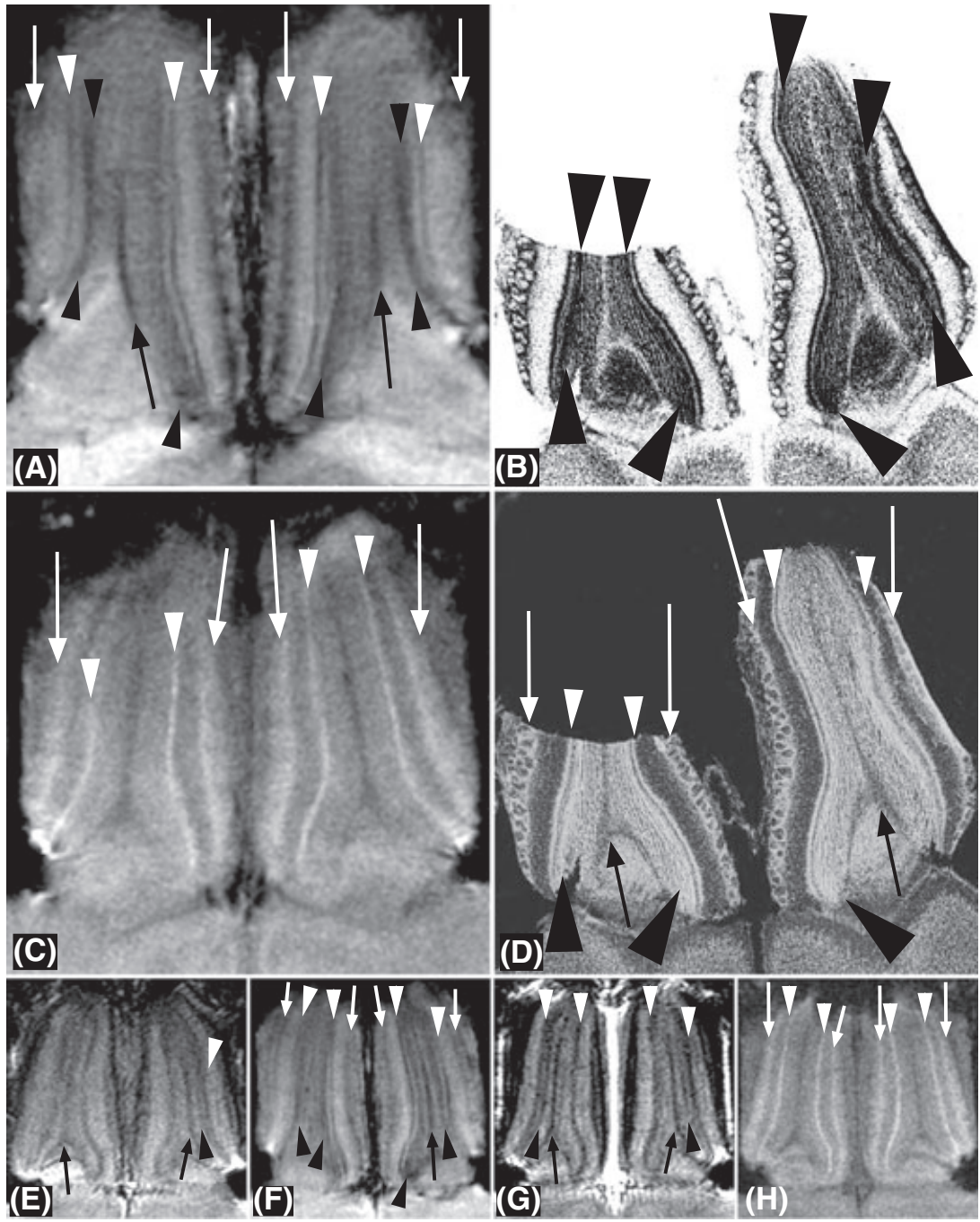

Figure 2. Olfactory bulb in horizontal sections. (A) $T_{1}$-weighted (T1W) MRI $\left(72 \mathrm{~min}, 25 \times 25 \times 250 \mu \mathrm{m}^{3}\right) 15$ - 87 min after gadopentetate dimeglumine (Gd-DTPA) administration. (B) Nissl stain of cell bodies (slide number 36 in (11)). (C) T1W MRI $\left(96 \mathrm{~min}, 25 \times 25 \times 250 \mu \mathrm{m}^{3}\right) 3$ days after MnCl 2 administration. (D) Nissl stain (contrast inverted). (E) $T_{2}$-weighted (T2W) MRI $\left(161 \mathrm{~min}, 30 \times 30 \times 300 \mu \mathrm{m}^{3}\right)$. (F) T1W MRI $\left(12 \mu \mathrm{min}, 30 \times 30 \times 300 \mu \mathrm{m}^{3}\right) 90-102 \mu \mathrm{min}$ after Gd-DTPA administration. (G) T2W MRI 2 days after $\mathrm{MnCl}_{2}$ injection. (H) T1W MRI $\left(12 \mathrm{~min}, 30 \times 30 \times 300 \mu \mathrm{m}^{3}\right) 2$ days after $\mathrm{MnCl}_{2}$ injection. Black arrows, white matter; white arrows, glomerular layers; black arrowheads, granule cell layers; white arrowheads, mitral cell layers. For details, see text.

granule cell layer despite a non-significant $(p=0.51)$ difference in Gd-DTPA enhancement. The enhancement by $\mathrm{Mn}^{2+}$ is also significantly $(p<0.005)$ higher for the stratum multiforme than the granule cell layer despite a significantly $(p<0.01)$ higher Gd-DTPA enhancement in the stratum. Further, the enhancement by $\mathrm{Mn}^{2+}$ is not significantly $(p=0.08)$ different between the granule cell layer and the stratum lacunosum-moleculare, although the enhancement by Gd-DTPA is significantly $(p<0.01)$ higher in the stratum lacunosum-moleculare. As a result, in the granule cell layer, pyramidal cell layer, stratum lacunosummoleculare, stratum lucidum, stratum multiforme and white matter, the normalized intensities are $1.00 \pm 0.12,1.38 \pm 0.19$, $0.79 \pm 0.07,1.48 \pm 0.13,1.59 \pm 0.20$ and $0.69 \pm 0.15(n=3)$, respectively, at a resolution of $25 \times 25 \times 250 \mu \mathrm{m}^{3}$.

Plain T2W MRI (Fig. 3E) provides a similar, but weaker, contrast than gadolinium-enhanced T1W MRI (Fig. 3F) despite a much longer measuring time. $\mathrm{Mn}^{2+}$ ions improve the contrast in $\mathrm{T} 2 \mathrm{~W}$ MRI (Fig. 3G) in agreement with the finding in T1W MRI (Fig. 3H). $\mathrm{Mn}^{2+}$ ions decrease the SNR in T2W MRI 2 days after injection by
$37 \%$ in the pyramidal cell layer, but by only $14 \%$ in the stratum lacunosum-moleculare, thereby increasing the respective CNR by $22 \%(n=4)$.

\section{Cerebellum}

Gadolinium-enhanced T1W MRI (Fig. 4A) leads to different signal intensities for the Purkinje cell layer, granule cell layer and molecular layer in agreement with histological staining (Fig. 4B). A difference from histology is seen for white matter, which presents with the lowest signal. In the granule cell layer, Purkinje cell layer, molecular layer and white matter, Gd-DTPA increases the SNR at 96 min after injection by 109\%, 48\%, 231\% and $44 \%$, respectively $(n=4)$. As a result, the corresponding normalized intensities are $0.74 \pm 0.07,0.52 \pm 0.04,1.17 \pm 0.10$ and $0.36 \pm 0.06(n=4)$ at a resolution of $30 \times 30 \times 300 \mu \mathrm{m}^{3}$.

Manganese-enhanced T1W MRI highlights the Purkinje cell layer in agreement with its dense staining (Fig. 4C), whereas the molecular layer and white matter are much less enhanced 

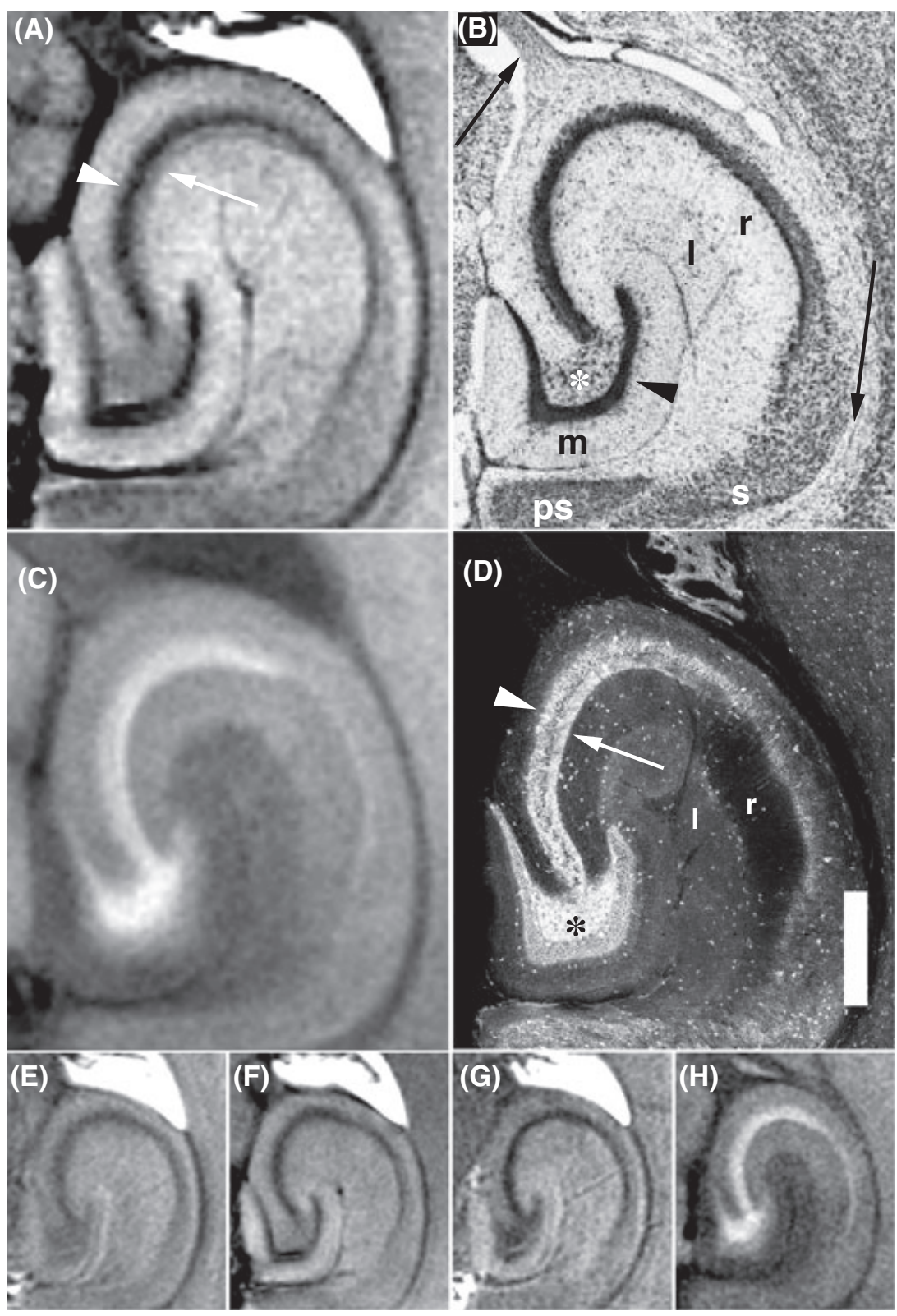

Figure 3. Hippocampal formation in horizontal sections. (A) $T_{1}$-weighted (T1W) MRI $\left(48 \mathrm{~min}, 25 \times 25 \times 250 \mu \mathrm{m}^{3}\right) 150-198$ min after gadopentetate dimeglumine (Gd-DTPA) administration. (B) Nissl stain (slide number 39 in (11)). (C) T1W MRI $\left(96 \mathrm{~min}, 25 \times 25 \times 250 \mu \mathrm{m}^{3}\right) 3$ days after $\mathrm{MnCl}_{2}$ administration. (D) Glutamic acid decarboxylase stain of cell bodies and mossy fibers (12) (scale bar, $400 \mu \mathrm{m})$. (E) $T_{2}$-weighted (T2W) MRI (161 min, $30 \times 30 \times 300 \mu \mathrm{m}^{3}$ ). (F) T1W MRI $\left(12 \mathrm{~min}, 30 \times 30 \times 300 \mu \mathrm{m}^{3}\right.$ ) 90-102 min after Gd-DTPA administration. (G) T2W MRI 2 days after $\mathrm{MnCl}_{2}$ injection. (H) T1W MRI (12 min, $\left.30 \times 30 \times 300 \mu \mathrm{m}^{3}\right) 3$ days after $\mathrm{MnCl}_{2}$ injection. Black arrow, white matter; white arrow, stratum lucidum; black arrowhead, granule cell layer; white arrowhead, pyramidal cell layer; asterisk, stratum multiforme; I, stratum lacunosum-moleculare; m, stratum moleculare; ps, parasubiculum; r, stratum radiatum; s, subiculum. For details, see text.

in agreement with their sparse staining (Fig. 4D). However, manganese-enhanced T1W MRI does not clearly enhance the granule cell layer despite its dense staining. In the granule cell layer, Purkinje cell layer, molecular layer and white matter, $\mathrm{Mn}^{2+}$ ions increase the SNR 2 days after injection by 18\%, 38\%, 13\% and $18 \%(n=4)$, respectively. In particular, the enhancement by $\mathrm{Mn}^{2+}$ is significantly $(p<0.05)$ higher for the Purkinje than for the granule cell layer, although the enhancements by Gd-DTPA are not significantly $(p=0.077)$ different. Further, the enhancement by $\mathrm{Mn}^{2+}$ is not significantly $(p=0.55)$ different between the granule cell and the molecular layer, although the enhancement by
Gd-DTPA is significantly $(p<0.05)$ higher for the molecular layer. As a result, in the granule cell layer, Purkinje cell layer, molecular layer and white matter, the normalized intensities are $0.89 \pm 0.07$, $1.49 \pm 0.06,0.98 \pm 0.06$ and $0.48 \pm 0.08(n=3)$, respectively, at a resolution of $30 \times 30 \times 300 \mu \mathrm{m}^{3}$. Plain T2W MRI (Fig. 4E) with $\mathrm{TE}=80 \mathrm{~ms}$ readily distinguishes the molecular and granule cell layer. $\mathrm{Mn}^{2+}$ ions delineate the Purkinje cell layer from the granule cell layer in T2W MRI (Fig. 4F) in agreement with the finding in T1W MRI (Fig. 4G). $\mathrm{Mn}^{2+}$ ions decrease the SNR in T2W MRI 2 days after injection by $33 \%$ in the Purkinje cell layer, but by only $16 \%$ in the stratum lacunosum-moleculare $(n=4)$. 


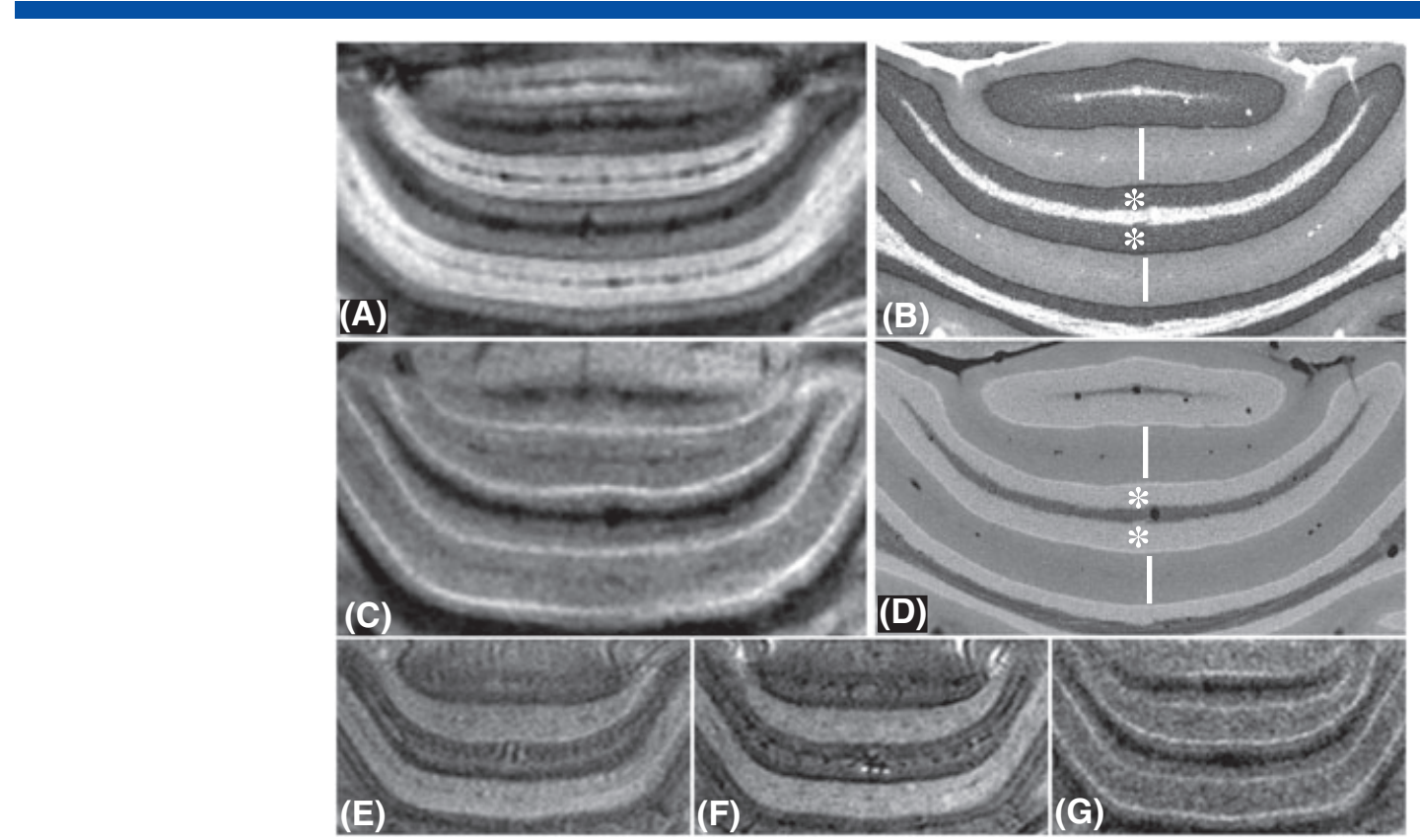

Figure 4. Cerebellum in horizontal sections. (A) $T_{1}$-weighted (T1W) MRI $\left(12 \mathrm{~min}, 30 \times 30 \times 300 \mu \mathrm{m}^{3}\right) 90-102$ min after gadopentetate dimeglumine (Gd-DTPA) administration. (B) Giemsa stain of cell bodies (slide number 18 in (11)). (C) T1W MRI (96 min, $30 \times 30 \times 300 \mu \mathrm{m}^{3}$ ) 3 days after $\mathrm{MnCl}_{2}$ administration. (D) Giemsa stain (contrast inverted). $T_{2}$-weighted (T2W) MRI $\left(161 \mathrm{~min}, 30 \times 30 \times 300 \mu \mathrm{m}^{3}, \mathrm{TE}=80 \mathrm{~ms}\right)$ before $(\mathrm{E})$ and 2 days after (F) $\mathrm{MnCl}_{2}$ injection. (G) T1W MRI $\left(12 \mathrm{~min}, 30 \times 30 \times 300 \mu \mathrm{m}^{3}\right) 2$ days after $\mathrm{MnCl}_{2}$ injection. Bars, molecular layers; asterisks, granule cell layers; between each asterisk and bar, Purkinje cell layer; between asterisks, white matter. For details, see text.

Figure 5 confirms the above findings in a different orientation for T1W MRI. In plain T2W MRI with TE $=48 \mathrm{~ms}$ (Fig. 5E), the contrast between the Purkinje and granule cell layer is improved relative to $\mathrm{TE}=80 \mathrm{~ms}$, whereas the signal reduction by $\mathrm{Mn}^{2+}$ ions in the Purkinje cell layer may be less clearly seen with the shorter TE (Fig. 5F).

\section{Neural tissues with different cellular composition}

Regardless of the region, comparisons of contrast-enhanced MRI with histological stains reveal that MRI signal enhancements depend to a large degree on the cellular composition of the tissue. In this respect, 20 tissue areas from three regions of the brain can be classified into five groups: (i) granule cell layers; (ii) principal cell layers; (iii) general neuropil; (iv) specialized neuropil; and (v) white matter. In gadolinium-enhanced MRI, the granule cell layers, principal cell layers and specialized neuropil present with low signal intensities, whereas general neuropil areas exhibit high signal intensities. In manganeseenhanced MRI, the granule cell layers and general neuropil show low signal intensities, whereas principal cell layers and specialized neuropil yield high signal intensities. White matter always presents with the lowest signal intensity, regardless of the region or contrast agent. Table 1 summarizes the mean signal intensities averaged across regions for each tissue composition. It is of note that the internal plexiform layer of the olfactory bulb, as well as the strata oriens, radiatum and moleculare of the hippocampal formation, can also be classified as general neuropil.

Principal cell layers are most clearly distinguished from general neuropil by gadolinium-enhanced T1W MRI. At a resolution of $30 \times 30 \times 300 \mu^{3}$, the mean CNRs between principal cell layers and general neuropil in the olfactory bulb, hippocampal formation and cerebellum are 8.6, 7.6 and $15(n=4)$, respectively.
The corresponding values for manganese-enhanced T1W MRI are 4.6, 6.0 and 4.8, whereas plain T2W MRI results in values of $3.9,6.3$ and 9.5, and manganese-enhanced T2W MRI in values of $6.0,7.6$ and 9.6. When considering $1 \mathrm{~min}$ as a unit measuring time, these values correspond to $0.72,0.63$ and 1.2 for gadolinium-enhanced T1W MRI, $0.39,0.50$ and 0.40 for manganese-enhanced T1W MRI, $0.024,0.039$ and 0.059 for plain T2W MRI, and 0.037, 0.047 and 0.059 for manganese-enhanced T2W MRI, respectively. Thus, compared with plain T2W MRI, gadolinium-enhanced T1W MRI provides a similar contrast, but with a 16-30-fold higher CNR. This finding originates from a drastic $T_{1}$ shortening of the tissue as a result of the extracellular distribution of Gd-DTPA. In the olfactory bulb, hippocampal formation, cerebellar cortex and somatosensory cortex, Gd-DTPA administration shortens the $T_{1}$ relaxation times $(n=3)$ from $1.48 \pm 0.12,1.59 \pm 0.07,1.44 \pm 0.08$ and $1.54 \pm 0.04 \mathrm{~s}$ to $0.43 \pm 0.10$, $0.42 \pm 0.20,0.44 \pm 0.11$ and $0.43 \pm 0.20 \mathrm{~s}$, respectively. Accordingly, the extracellular space in the left hippocampal formation and cerebellar cortex can be estimated to be $18 \%$.

\section{DISCUSSION}

The present work compares gadolinium-enhanced T1W MRI (about $1.0 \mu \mathrm{mol}$ Gd-DTPA/g brain), manganese-enhanced T1W MRI, plain T2W MRI and manganese-enhanced T2W MRI of the mouse brain at 9.4 T. Previous MRI studies of Gd-DTPA injections into the extracellular fluid of the brain reported no significant histological abnormality in animals after the injection of $2.5-10 \mu \mathrm{mol} / \mathrm{g}$ brain, as well as no specific complications in more than 100 human patients after the injection of $0.007-0.36 \mu \mathrm{mol} / \mathrm{g}$ brain (21-28). In addition, intravenous administration of gadolinium-based contrast agents is widely used to assess an impaired blood-brain barrier, where the agents reach the 


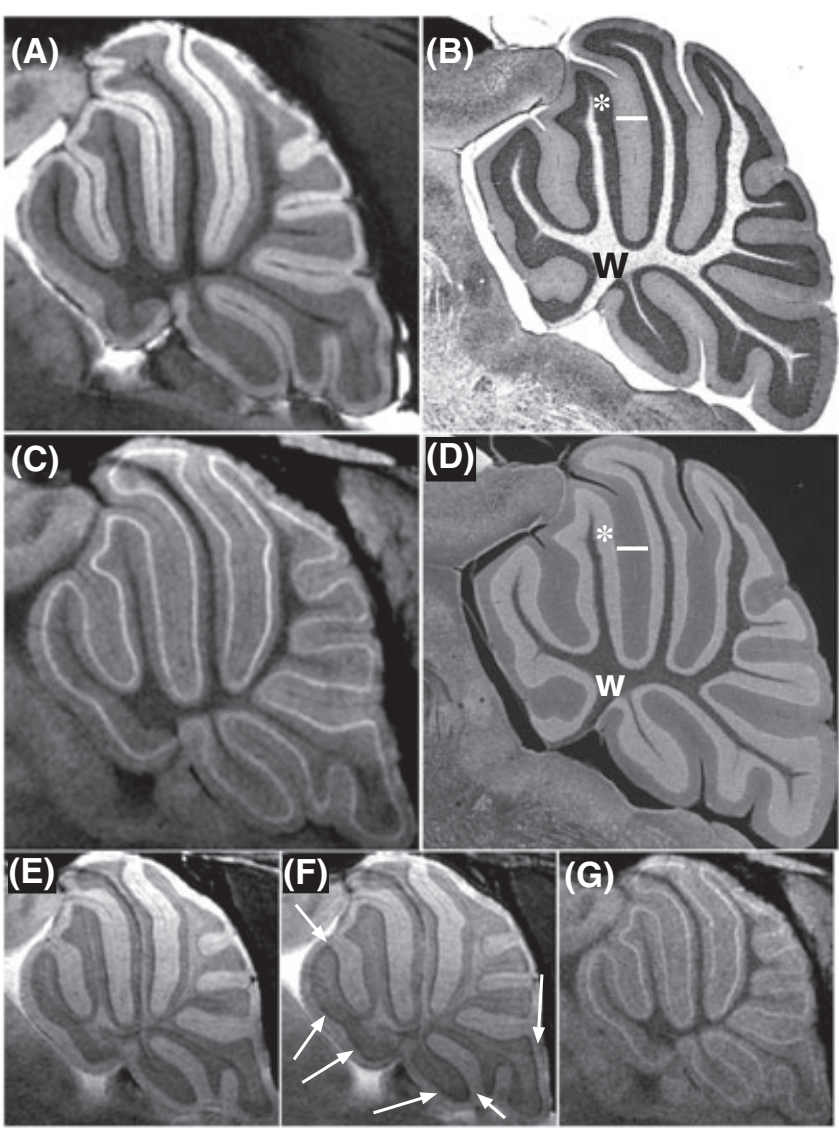

Figure 5. Cerebellum in sagittal sections. (A) $T_{1}$-weighted (T1W) MRI (12 min, $30 \times 30 \times 300 \mu \mathrm{m}^{3}$ ) 105-117 min after gadopentetate dimeglumine (Gd-DTPA) administration. (B) Giemsa stain of cell bodies (slide number 79 in (11)). (C) T1W MRI $\left(96 \mathrm{~min}, 30 \times 30 \times 300 \mu \mathrm{m}^{3}\right) 3$ days after $\mathrm{MnCl}_{2}$ administration. (D) Giemsa stain (contrast inverted). $T_{2}$-weighted (T2W) MRI ( $\left.161 \mathrm{~min}, 30 \times 30 \times 300 \mu \mathrm{m}^{3}, \mathrm{TE}=48 \mathrm{~ms}\right)$ before $(\mathrm{E})$ and 2 days after (F) $\mathrm{MnCl}_{2}$ injection. (G) T1W MRI $\left(12 \mathrm{~min}, 30 \times 30 \times 300 \mu \mathrm{m}^{3}\right) 2$ days after $\mathrm{MnCl}_{2}$ injection. White arrows, signal reduction caused by accumulated manganese in parts of the Purkinje cell layer; bars, molecular layers; asterisks, granule cell layers; W, white matter. For details, see text.

extracellular fluid. However, enhancement of the contrast between cellular layers and neuropil has not been described to date.

This work shows that gadolinium-enhanced T1W MRI and plain T2W MRI provide a similar contrast, which supports the view that contrast in T2W MRI of the brain mainly reflects the extracellular fluid content. Moreover, it has been demonstrated that $\mathrm{Mn}^{2+}$ ions enhance the contrast in the brain of behaving animals not only in T1W MRI, as widely used so far, but also in T2W MRI.

Contrast-enhanced T1W MRI provides substantially higher CNR per measuring time than does T2W MRI, and therefore allows acquisitions at voxel sizes of $25 \times 25 \times 250 \mu \mathrm{m}^{3}$. Such recordings reveal distinct signal patterns of five different tissue types after Gd-DTPA injection or $\mathrm{Mn}^{2+}$ administration. The contrast provided by Gd-enhanced MRI in gray matter is in excellent agreement with histological stains of intracellular substance. This finding suggests that the underlying contrast mechanism mainly reflects water protons in intra- and extracellular spaces. However, the contrast provided by $\mathrm{Mn}^{2+}$-enhanced MRI clearly differs from that seen in histology. This discrepancy indicates that the signal increase after manganese administration reflects cellular activity which is disproportionate to the intracellular space.

\section{Granule cell layers}

In all three brain regions studied, there are granule cells which exhibit a characteristic smallness of their cell bodies. In the olfactory bulb, hippocampal formation and cerebellum of mice, the mean diameters of granule cell bodies have been reported to be $6.5 \mu \mathrm{m}(29), 5-6 \mu \mathrm{m}(30,31)$ and $5.8 \mu \mathrm{m}(32)$, respectively. Their axons are thin, short and barely myelinated. In the olfactory bulb, they are even axonless. The present work shows that $\mathrm{Mn}^{2+}$ ions enhance the granule cell layer no more than general neuropil and significantly less than principal cell layers, although the low signal intensity of the granule cell layers in gadoliniumenhanced MRI confirms the presence of large intracellular spaces caused by tight packing. These findings suggest a limited activity for the cells to take up $\mathrm{Mn}^{2+}$ ions.

\section{Principal cell layers}

In each of the three regions studied, there is a cellular layer with highly specialized neurons which are among the largest in the body, i.e. the mitral cell layer in the olfactory bulb, the pyramidal cell layer in the hippocampal formation and the Purkinje cell layer in the cerebellum. The diameters of their cell bodies are 15-30 $\mu \mathrm{m}$ (33), 15-20 $\mu \mathrm{m}$ (34) and $16 \mu \mathrm{m}$ (35), respectively. Bodies of pyramidal cells in the CA3 area are even larger (36). In addition, there are several common features known for these cells: (i) they are tightly packed as a layer which is no thicker than a few cell bodies; (ii) they receive glutamatergic excitatory inputs

Table 1. Signal intensities of neural tissues with different cellular composition in contrast-enhanced $T_{1}$-weighted $M R I$ using gadopentetate dimeglumine (Gd-DTPA) and manganese

\begin{tabular}{|c|c|c|c|c|}
\hline Tissue & & Region of interest & Gd-DTPA $(n=4)$ & $\mathrm{MnCl}_{2}(n=3)$ \\
\hline \multirow[t]{2}{*}{ Cell layers } & Granule & Granule cell layers $(\mathrm{OB}, \mathrm{HF}, \mathrm{Ce})$ & $0.72 \pm 0.06$ & $0.86 \pm 0.09$ \\
\hline & Principal & Mitral (OB), pyramidal (HF) and Purkinje (Ce) cell layers & $0.64 \pm 0.02$ & $1.34 \pm 0.15$ \\
\hline \multirow[t]{2}{*}{ Neuropil } & General & $\begin{array}{l}\text { External plexiform layer (OB), stratum lacunosum-moleculare } \\
(\mathrm{HF}) \text {, molecular layer (Ce) }\end{array}$ & $1.12 \pm 0.06$ & $0.83 \pm 0.05$ \\
\hline & Specialized & Glomerular layer (OB), strata lucidum and multiforme (HF) & $0.85 \pm 0.03$ & $1.36 \pm 0.10$ \\
\hline White matter & & White matter (OB, HF, Ce) & $0.50 \pm 0.02$ & $0.57 \pm 0.09$ \\
\hline
\end{tabular}


from multiple sources $(4,37,38)$; (iii) their excitatory inputs induce $\mathrm{Ca}^{2+}$ influx-dependent long-lasting modification of synaptic efficacy which is involved in learning (39-43); and (iv) their long myelinated axons form a large bundle leaving the region as its main output. The low signal intensity of these cellular layers in gadolinium-enhanced MRI of each region confirms the large intracellular spaces caused by tight packing. Under these circumstances, $\mathrm{Mn}^{2+}$ ions are probably taken up into the excited cells $(10,44)$ and therefore become concentrated in the thin layer.

\section{General neuropil}

Layers of neuropil are composed of axons, dendrites and a small number of cell bodies, which are not tightly packed. They refer to the internal and external plexiform layers in the olfactory bulb, the strata oriens, radiatum, lacunosum-moleculare and moleculare in the hippocampal formation, and the molecular layer in the cerebellum. These neuropil areas have large extracellular and small intracellular spaces, which can explain the high and low signal intensities in gadolinium- and manganese-enhanced MRI, respectively. In particular, Gd-DTPA effectively highlights the thin internal plexiform layer and thus distinguishes the mitral and granule cell layer in the olfactory bulb. Even in histology, the internal plexiform layer cannot clearly be identified as a separate layer in some places (4). Indeed, the clear in vivo depiction of this layer in the present study suggests a considerable shrinkage of the layer during ex vivo histological processing.

\section{Specialized neuropil receiving dense synaptic input}

Specialized cells receive substantial excitatory synaptic input onto their dendrites. In the olfactory bulb, each mitral cell has a single primary dendrite entering a glomerulus, which is assembled to form the glomerular layer receiving primary synaptic inputs from the axons of the olfactory receptor cells. Similarly, in the hippocampal formation, the pyramidal cells receive massive synaptic input into the dendrites of the stratum lucidum from the mossy fibers which arrive through the stratum multiforme. These synapses commonly possess: (i) spherical synaptic vesicles and asymmetric membrane specializations (type I of Gray); (ii) dense glutamatergic excitatory inputs from unmyelinated fibers; (iii) $\mathrm{N}$-methyl-D-aspartate receptors as postsynaptic ionotropic glutamate receptors, whose activation causes a large $\mathrm{Ca}^{2+}$ influx; (iv) long-term potentiation of synaptic responses $(39,40,42)$; and (v) recurrent and reciprocal glutamatergic excitatory inputs $(37,38)$. In the cerebellum, by contrast, the Purkinje cells receive inputs rather diffusely in the cortex encompassing the entire molecular and Purkinje layers. Neither the $\mathrm{N}$-methyl-D-aspartate receptor nor long-term potentiation has been reported for these cells (45). Their main recurrent inputs are rather inhibitory (46).

In gadolinium-enhanced MRI, the specialized neuropil areas in the olfactory bulb and hippocampal formation present with lower signal intensities than does general neuropil. In particular, the stratum lucidum, not identified by Nissl staining, can be delineated from the adjacent general neuropil, i.e. stratum radiatum, because of its larger intracellular spaces. Nevertheless, these specialized neuropil areas are enhanced by Gd-DTPA no less than cell layers of each region, which indicates that their intracellular spaces are no larger than those of cell layers. However, the enhancements in specialized neuropil by $\mathrm{Mn}^{2+}$ ions are significantly higher than those in granule cell layers and no lower than those in principal cell layers. This shows that not only a cellular layer, but also a neuropil area, provided that it receives a concentrated synaptic input, can be highlighted by $\mathrm{Mn}^{2+}$ ions despite its smaller intracellular space. In fact, it has been shown that a disruption of synaptic input results in a significantly reduced enhancement of specialized neuropil areas, which are otherwise strongly enhanced by the systemic administration of manganese (47).

\section{White matter}

White matter has substantially lower water content (about 70\%) than gray matter $(>80 \%)$. This is mainly because of the smaller extracellular spaces in white matter than in gray matter, as shown previously (14). Thus, tissue packed with myelinated nerve fibers generally presents with low signal intensity after Gd-DTPA administration. The lower signal intensity of white matter after $\mathrm{Mn}^{2+}$ administration indicates limited fluid space for the ions to diffuse. In other words, myelin sheaths hinder the diffusion of $\mathrm{Mn}^{2+}$ ions (48).

\section{CONCLUSIONS}

Contrast-enhanced MRI of the brain of living animals by Gd-DTPA and manganese provides new insights into neurohistology. It may also contribute to neuroradiology because the resulting high CNR and access to high spatial resolution help to better understand the mechanisms and structures determining the $T_{1}$ and $T_{2}$ MRI contrast in general. For example, the similarities observed for gadolinium-enhanced MRI and T2W MRI confirm that $T_{2}$ contrast mainly reflects the extracellular fluid content in tissue. Thus, not only in gadolinium-enhanced MRI, but also in T2W MRI, the granule cell layer, principal cell layer, specialized neuropil and white matter present with low signal intensity, whereas the general neuropil areas exhibit high signal intensity. Further, the present results for gadolinium-enhanced MRI may be relevant for the diagnosis of an impaired blood-brain barrier, whereas the findings for manganese-enhanced T2W MRI may be of importance in the diagnosis of manganese poisoning.

For principal cell layers, general neuropil and white matter, the interpretation of contrast-enhanced MRI is straightforward. The pattern for both Gd-DTPA and manganese enhancement is in excellent agreement with the relative distribution of intracellular and extracellular spaces. However, for granule cells and specialized neuropil, there are obvious discrepancies between contrasts in manganese-enhanced MRI and histology. Contrary to expectations, granule cells and principal cells react differently towards $\mathrm{Mn}^{2+}$ ions, as do general and specialized neuropil. However, granule cells behave like myelinated fibers not only towards Gd-DTPA, but also towards $\mathrm{Mn}^{2+}$ ions, whereas specialized neuropil behaves like principal cells.

The present study focuses on three regions which show distinct layers of different cellular composition. These regions are known to possess a relatively simple and primitive configuration with a clear differentiation into layers. Indeed, MRI delineates these regions with the highest CNR in the brain. Nevertheless, the results are applicable to the entire central nervous system because the cellular compositions of other brain regions, which are less distinctly differentiated into zones, are in between those of cell layers and neuropil as described here. It is foreseeable that the present approach will contribute to further unveil the cytoarchitecture of the brain of mammals in vivo, ranging from transgenic mice to humans. 


\section{REFERENCES}

1. Petit A, Santin M, Bertrand A, Wiggins CJ, Petit F, Houitte D, Hantraye $\mathrm{P}$, Benavides J, Debeir T, Rooney T, Dhenain M. Gadolinium-staining reveals amyloid plaques in the brain of Alzheimer's transgenic mice. Neurobiol. Aging, 2012; 33: 1533-1544.

2. Johnson GA, Cofer GP, Gewalt SL, Hedlund LW. Morphologic phenotyping with MR microscopy: the visible mouse. Radiology, 2002; 222: 789-793.

3. Ullmann JFP, Watson $C$, Janke AL, Kurniawan ND, Reutens DC. A segmentation protocol and MRI atlas of the $C 57 \mathrm{BL} / 6 \mathrm{~J}$ mouse neocortex. Neuroimage, 2013; 78: 196-203.

4. Nieuwenhuys R, Ten Donkelaar HJ, Nicholson C. The central nervous system of vertebrates, Vol. 3. Springer: Berlin-Heidelberg; 1998.

5. Schoeniger JS, Aiken N, Hsu E, Blackband SJ. Relaxation-time and diffusion NMR spectroscopy of single neurons. J. Magn. Reson. B, 1994; 103: 261-273.

6. Benveniste $H$, Blackband S. MR microscopy and high resolution small animal MRI: applications in neuroscience research. Prog. Neurobiol. 2002; 67: 393-420.

7. Watanabe T, Frahm J, Michaelis T. Functional mapping of neural pathways in rodent brain in vivo using manganese-enhanced three-dimensional MRI. NMR Biomed. 2004; 17: 554-568.

8. Boretius S, Kasper L, Tammer R, Michaelis T, Frahm J. MRI of cellular layers in mouse brain in vivo. Neuroimage, 2009; 47: 1252-1260.

9. Baltes C, Radzwill N, Bosshard S, Marek D, Rudin M. Micro MRI of the mouse brain using a novel $400 \mathrm{MHz}$ cryogenic quadrature RF probe. NMR Biomed. 2009; 22: 834-842.

10. Koretsky AP, Silva AC. Manganese-enhanced magnetic resonance imaging (MEMRI). NMR Biomed. 2004; 17: 527-531.

11. Mikula S, Trotts I, Stone JM, Jones EG. Internet-enabled high-resolution brain mapping and virtual microscopy. Neuroimage, 2007; 35: 9-15. Available at: http://brainmaps.org [accessed January 2013]

12. Jinno S, Aika Y, Fukuda T, Kosaka T. Quantitative analysis of GABAergic neurons in the mouse hippocampus, with optical disector using confocal laser scanning microscope. Brain Res. 1998; 814: 55-70.

13. Watanabe T, Tammer R, Boretius S, Frahm J, Michaelis T. Chromium(VI) as a novel MRI contrast agent for cerebral white matter: preliminary results in mouse brain in vivo. Magn. Reson. Med. 2006; 56: 1-6.

14. Watanabe T, Frahm J, Michaelis T. Myelin mapping in the central nervous system of living mice using contrast-enhanced magnetization transfer MRI. Neuroimage, 2012; 63: 812-817.

15. Watanabe T, Radulovic J, Spiess J, Natt O, Boretius S, Frahm J, Michaelis T. In vivo 3D MRI staining of the mouse hippocampa system using intracerebral injection of $\mathrm{MnCl}_{2}$. Neuroimage, 2004; 22: 860-867.

16. Tammer R, Boretius S, Michaelis T, Pucher-Diehl A. MRI compatible animal holder. European Patent Application, 2007; EP2007/006820, US Patent Application pending.

17. Pappius HM. Water spaces. In: Lajtha A (ed.). Handbook of Neurochemistry. Vol. 1. Chemical and Cellular Architecture. Plenum Press: New York; 1982, pp. 139-149.

18. Koenig SH, Brown III RD, Spiller M, Lundbom N. Relaxometry of brain: why white matter appears bright in MRI. Magn. Reson. Med. 1990; 14: 482-495.

19. Donahue KM, Burstein D, Manning WJ, Gray ML. Studies of Gd-DTPA relaxivity and proton exchange rates in tissue. Magn. Reson. Med. 1994; 32: 66-76.

20. Yao X, Hrabětová S, Nicholson C, Manley GT. Aquaporin-4-deficient mice have increased extracellular space without tortuosity change. J. Neurosci. 2008; 28: 5460-5464.

21. Aydin K, Guven K, Sencer S, Jinkins JR, Minareci O. MRI cisternography with gadolinium-containing contrast medium: its role, advantages and limitations in the investigation of rhinorrhoea. Neuroradiology, 2004; 46: 75-80.

22. Jinkins JR, Rudwan M, Krumina G, Tali ET. Intrathecal gadoliniumenhanced MR cisternography in the evaluation of clinically suspected cerebrospinal fluid rhinorrhea in humans: early experience. Radiology, 2002; 222: 555-559.

23. Joseph V, Raghuram L, Korah IP, Chacko AG. MR ventriculography for the study of CSF flow. Am. J. Neuroradiol. 2003; 24: 373-381.

24. Mavioglu H, Tuglu I, Temiz C, Ozbilgin K, Cilaker S, Selcuki D, Selcuki M. Clinical and histological changes of intrathecally administered gadopentate dimeglumine (Gd-DTPA) in normal rats. Riv. Neuroradiol. 2005; 18: 521-528.
25. Reiche W, Komenda Y, Schick B, Grunwald I, Steudel W, Reith W. MR cisternography after intrathecal Gd-DTPA application. Eur. Radiol. 2002; 12: 2943-2949.

26. Siebner HR, Gräfin von Einsiedel H, Conrad B. Magnetic resonance ventriculography with gadolinium DTPA: report of two cases. Neuroradiology, 1997; 39: 418-422.

27. Tali ET, Ercan N, Krumina G, Rudwan M, Mironov A, Zeng QY, Jinkins $J R$. Intrathecal gadolinium (gadopentate dimeglumine) enhanced magnetic resonance myelography and cisternography. Invest. Radiol. 2002; 37: 152-159.

28. Toney GM, Chavez HA, Ibarr R, Jinkins JR. Acute and subacute physiological and histological studies of the central nervous system after intrathecal gadolinium injection in the anesthetized rat. Invest. Radiol. 2001; 36: 33-40.

29. Gheusi G, Cremer H, McLean H, Chazal G, Vincent JD, Lledo PM. Chazal G, Vincent JD, Lledo PM. Importance of newly generated neurons in the adult olfactory bulb for odor discrimination. Proc. Natl. Acad. Sci. U. S. A., 2000; 97: 1823-1828.

30. Aggarwal M, Mori S, Zhang J. Probing microscopic cellular architecture in the mouse brain by oscillating gradient diffusion tensor imaging. Proceedings of the 19th Annual Meeting ISMRM, Montreal, QC, Canada, 2011; 81.

31. Wadiche LSO, Bensen AL, Westbrook GL. Delayed development of adult-generated granule cells in dentate gyrus. J. Neurosci. 2006; 26: 2326-2334.

32. Diwakar S, Magistretti J, Goldfarb M, Naldi GE. Axonal $\mathrm{Na}^{+}$channels ensure fast spike activation and back-propagation in cerebellar granule cells. J. Neurophysiol. 2009; 101: 519-532.

33. Mast TG, Fadool DA. Mature and precursor brain-derived neurotrophic factor have individual roles in the mouse olfactory bulb. PLoS ONE, 2012; 7: e31978.

34. Bonin RP, Martin $L$, MacDonald JF, Orser BA. $\alpha 5 G A B A_{A}$ receptors regulate the intrinsic excitability of mouse hippocampal pyramidal neurons. J. Neurophysiol. 2007; 98: 2244-2254.

35. Triarhou LC, Norton J, Ghetti B. Anterograde transsynaptic degeneration in the deep cerebellar nuclei of Purkinje cell degeneration (pcd) mutant mice. Exp. Brain Res. 1987; 66: 577-588.

36. Stanfield BB, Cowan WM. The morphology of the hippocampus and dentate gyrus in normal and reeler mice. J. Comp. Neurol. 1979; 185: 393-422.

37. Didier A, Carleton A, Bjaalie JG, Vincent JD, Ottersen OP, Mathisen JS, Lledo PM. A dendrodendritic reciprocal synapse provides a recurrent excitatory connection in the olfactory bulb. Proc. Natl. Acad. Sci. U. S. A., 2001; 98: 6441-6446.

38. Lisman JE. Relating hippocampal circuitry to function: recall of memory sequences by reciprocal dentate-CA3 interactions. Neuron, 1999; 22: 233-242.

39. Ennis M, Linster C, Aroniadou-Anderjaska V, Ciombor K, Shipley MT. Glutamate and synaptic plasticity at mammalian primary olfactory synapses. Ann. N. Y. Acad. Sci. 1998; 855: 457-466.

40. Lethbridge R, Hou Q, Harley CW, Yuan Q. Olfactory bulb glomerular NMDA receptors mediate olfactory nerve potentiation and odor preference learning in the neonate rat. PLoS ONE, 2012; 7: e35024.

41. Lüscher C, Huber KM. Group 1 mGluR-dependent synaptic long-term depression: mechanisms and implications for circuitry and disease. Neuron, 2010; 65: 445-459.

42. Xiang Z, Greenwood AC, Kairiss EW, Brown TH. Quantal mechanism of long-term potentiation in hippocampal mossy-fiber synapses. J. Neurophysiol. 1994; 71: 2552-2556.

43. Zigmond MJ, Bloom FE, Landis SC, Roberts JL, Squire LR. Fundamental Neuroscience. Academic Press: San Diego, CA; 1999.

44. Lin YJ, Koretsky AP. Manganese ion enhances T1-weighted MRI during brain activation: an approach to direct imaging of brain function. Magn. Reson. Med. 1997; 38: 378-388.

45. Miyawaki $\mathrm{H}, \mathrm{Hirano} \mathrm{T}$. Different correlations among physiological and morphological properties at single glutamatergic synapses in the rat hippocampus and the cerebellum. Synapse, 2011; 65: 412-423.

46. Manto MU, Pandolfo M. The Cerebellum and its Disorders. Cambridge University Press: Cambridge, 2002.

47. Watanabe T, Schachtner J, Krizan M, Boretius S, Frahm J, Michaelis T. Manganese-enhanced 3D MRI of established and disrupted synaptic activity in the developing insect brain in vivo. J. Neurosci. Methods, 2006; 158: 50-55.

48. Watanabe T, Frahm J, Michaelis T. Myelin mapping in the living mouse brain using manganese-enhanced magnetization transfer MRI. Neuroimage, 2010; 49: 1200-1204. 